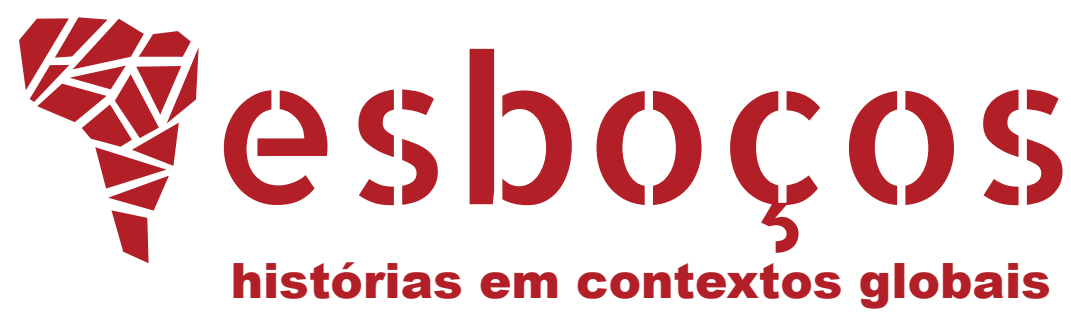

\title{
ACERTOS E DESAFIOS DE UMA \\ PERSPECTIVA GLOBAL DA HISTÓRIA DA INFÂNCIA E DAS EMOÇÕES
}

Achievements and challenges of a global perspective on the history of childhood and emotions

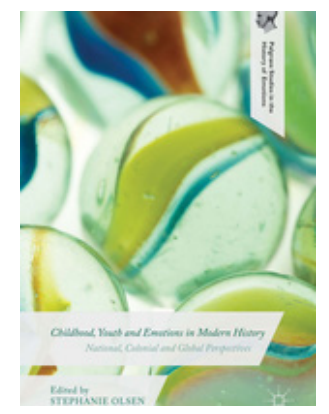

OLSEN, Stephanie (ed.) Children, youth and emotions in modern history: national, colonial and global perspectives. Basingstoke: Palgrave Macmillan, 2015. 264 p.

PALAVRAS CHAVE: História global. Infância. Emoções.

KEYWORDS: Global history. Childhood. Emotions. 
inda pouco expressivo no conjunto da produção historiográfica brasileira, o estudo das emoções estruturou-se, sobretudo na Europa, como campo específico do saber histórico, fundado, principalmente, em diálogos interdisciplinares com a Psicologia e os estudos da Educação, que procuram desvendar a historicidade das emoções e sua importância no curso de transformações e permanências históricas. Publicado em 2015, Children, Youth and Emotions in Modern History é uma interessante compilação de estudos da área organizada por Stephanie Olsen, professora da Universidade McGill, no Canadá, então pesquisadora do Max Planck Institute for Human Development, de Berlim. A coletânea é fruto de uma conferência de mesmo título organizada em 2012 pelo Centro de Estudos da História das Emoções do Max Planck Institute.

O projeto do livro é ambicioso. Sua anunciada pretensão é oferecer "contribuições teórico-metodológicas inovadoras, capazes de fazer avançar a agenda da História da Infância por meio da História das Emoções", a partir de uma perspectiva global, defendida na Introdução do livro e, principalmente, no capítulo 2, de autoria da organizadora do volume em parceria com Karen Vallgarda e Kristine Alexander. Beneficiando-se do deslocamento do foco geográfico tradicional dos estudos da área, por longo tempo centrados nas realidades norte-americana e inglesa, e valendo-se da adoção de perspectivas coloniais, pós-coloniais e não ocidentais, a abordagem global e comparada do tema evidenciaria a articulação entre as emoções constitutivas da experiência e das concepções de infância e as realidades históricas ampliadas relacionadas, sobretudo, às dinâmicas do capitalismo internacional e à vulgarização do ideário liberal entre o início do século XIX e a metade do século XX. Assim, tal abordagem teria como efeito o questionamento de definições universais de infância, por um lado, e a articulação de uma história da infância menos etnocêntrica, por outro.

Não obstante a absoluta relevância da proposta teórica em tela, chama a atenção o fato de que, dos doze capítulos que se seguem, sete referem-se a dinâmicas nacionais, coloniais e pós-coloniais da Inglaterra ou de domínios do Império Britânico entre o final do século XIX e a metade do século XX - Uganda, Índia, e Nova Zelândia são cenários contemplados pelos capítulos em questão. Somando-se a eles um capítulo que trata dos Estados Unidos de inícios do século XX, contam-se oito seções a respeito de sociedades anglófonas. Completam a reunião de estudos um capítulo sobre a Alemanha pós Segunda Guerra, um sobre a China da Segunda Guerra Sino-japonesa e, finalmente, um capítulo a respeito da Colômbia das décadas de Independência, no início do século XIX. A lacuna criada pela limitada representatividade da América Latina entre os capítulos, que fala a pesquisadores nativos dessa região mais diretamente, associa-se à ausência de discussões - ou mesmo referências passageiras - à infância negra ou indígena, livre ou escravizada, que constitui parte fundamental das formas de ser e conceber a criança nas Américas. Finalmente, sublinhando tais lacunas, há a ampla predominância de pesquisadores oriundos de universidades ou institutos de pesquisa euro-americanos, sendo nove deles de instituições anglófonas - exceções feitas a Rob Kozlovsky, da Universidade de Tel Aviv, e à Karen Vallgarda, da Universidade de Copenhague.

É fato que o interesse na perspectiva global pode prescindir, por definição, da apreciação de contextos que correspondam imediata e limitadamente aos objetos de estudo de leitores e pesquisadores; é justamente a possibilidade de transcender limites exclusivamente locais ou nacionais, levando em consideração realidades diversas, 
apenas aparentemente ou francamente díspares daquelas que se estuda, uma das maiores potencialidades e contribuições de abordagens dessa afiliação. ${ }^{1}$ Registrese, não obstante, a necessidade de avançar um diálogo mais diverso e inclusivo dos contextos pesquisados, que amplie possibilidades de pensar a construção da infância moderna em perspectiva verdadeiramente global e renovadora da história da infância, pretensão textualmente anunciada no capítulo inaugural "Emotions and the Global Politics of Childhood".

Buscando estabelecer as bases metodológicas das discussões que o seguem, o capítulo em questão lança-se ainda à tarefa de circunscrever conceitos tidos como estruturantes para as análises da história das emoções. Partindo do pressuposto de que as experiências emocionais não podem ser separadas das normatividades sociais que as definem, as autoras circunscrevem conceitos capazes de apreender tais imbricações em perspectiva global. O conceito de emotional formation se refere a estruturas ou padrões emocionais hierarquizados, ao mesmo tempo socialmente subjetivados e socialmente partilhados, ao passo que o conceito de emotional frontier refere-se a "fronteiras entre diferentes formações emocionais" potencialmente causadoras de conflitos. É inevitável perceber que o esforço de definição destas nomenclaturas torna-se um tanto vão ao longo dos textos que se seguem. Poucas são as referências feitas a elas nos diversos capítulos do livro, dando os autores preferência ao uso dos mais célebres - e, ao que parece, amplamente suficientes - conceitos de emotionology e, principalmente, emotional regime e emotional community, criados respectivamente por Peter e Carol Stearns, William E. Reddy e Barbara Rosenwein (STEARNS; STEARNS, 1985; REDDY, 1997; ROSENWEIN, 2002). Estes dão conta, grosso modo, dos debates em torno das normatividades e práticas emocionais, sua ligação com estruturas de poder e com a composição de identidades comunais.

Assim como a necessidade de criar novos conceitos para o campo da história das emoções parece artificial, a ausência de reflexões acerca das contribuições teóricas estruturantes do campo da história da infância num capítulo que se dedica a estabelecer as bases teórico-metodológicas do livro soa também estranha. É fato que já há muitas décadas intelectuais dedicados ao tema da infância têm consistentemente criticado e superado os paradigmas da "descoberta da infância" definidos por Philippe Ariès em sua obra seminal (ARIÈS, 1981; FLANDRIN, 1964; HEYWOOD, 2004; KHULMANN JR.; FERNANDES, 2004). É também verdade, no entanto, que sua original percepção da historicidade da imaginação social da infância lançou as bases para o questionamento da condição infantil universal, que se desdobrou, ao longo das décadas, em uma rica literatura sobre a infância em diversas áreas das Ciências Humanas - o que faz do autor e de sua obra referências incontornáveis. ${ }^{2}$ Não obstante, apenas no sexto capítulo do livro surge a primeira e única reflexão crítica sobre as contribuições de Ariès.

Tais ressalvas iniciais não invalidam, decerto, o interessante leque temático apresentado pela obra. Com recortes temáticos e metodológicos diversos, os capítulos

\footnotetext{
${ }^{1}$ A respeito das intersecções entre infância e história global, ver o artigo de Raymond Grew (2005) initulado "On seeking global history's inner child".

2 Sua influência é sentida na Sociologia e na Antropologia da Infância (JAMES; PROUT, 1990; HARDMAN, 2001; COHN, 2013).
} 
do livro abrangem as relações estabelecidas entre as práticas e normatividades sociais consubstanciadas na idealização de emoções, e as concepções e (com menor ênfase) experiências de infância produzidas em condições variadas entre os séculos XIX e XX. As profundas imbricações entre imperialismo, nação e nacionalismo e infância dão a tônica do volume como um todo. A reelaboração de concepções ocidentais de infância e papeis familiares na Índia colonial é tema dos artigos de Ishita Prandi (capítulo 3) e Swapna M. Banerjee (capítulo 12). Neles, os autores demonstram como o corolário da família vitoriana penetra a colônia e frequenta os discursos de intelectuais locais, sendo reelaborado em termos de subjetividades coloniais modernas que designam novos contornos para a afetividade e os vínculos familiares. Investindo num recorte de gênero, o artigo de Prandi revela, ainda, como estas transformações incidem, no caso das meninas precocemente casadas, sobre a própria definição dos limites da infância e da sexualidade, abrindo espaço para uma disputa entre visões tradicionais e modernas, de pretensão "civilizatória", em torno do casamento infantil.

A disciplina do corpo infantil e de seus sentimentos é também objeto de capítulos muito interessantes que tratam das relações entre infância e espaço em dois contextos bastante distintos. Reportando-se aos estudos da história da arquitetura, Roy Kozlovsky (capítulo 6) investiga as interseções entre a reconstrução física da Inglaterra após a Segunda Guerra Mundial e a reconstrução política da cidadania inglesa por meio de instituições de educação e cuidados da infância. O uso do espaço como elemento de disciplinamento do corpo, de educação das emoções e das relações afetivas no estado de bem-estar social reporta-se, como demonstra seu interessante artigo, à própria reconstrução da Europa pós-guerra. O domínio e a educação das emoções por meio do controle do corpo é tema, também, do capítulo de Jane Hamlett (capítulo 7), que versa sobre a arquitetura dos dormitórios de colégios vitorianos frequentados por meninos da elite. Em diálogo com as reflexões foucaultianas sobre as instituições modernas de controle social, Hemlett demonstra como o espaço constituiu-se em elemento exterior de constrangimento às normas de comportamento, moralidade $\mathrm{e}$ sexualidade e, por conseguinte, de disciplinamento da subjetividade das crianças e jovens internos. ${ }^{3}$

A educação das emoções infantis para a construção de cidadanias modernas é também tema central de outros capítulos. Discutindo o repositório iluminista que frequenta os debates políticos da Colômbia republicana nas primeiras décadas do século XIX, Marcelo Caruso (capítulo 8) explora a associação entre a emergência de regimes políticos e a afirmação de regimes emocionais - ou seja, de formas dominantes de ideação e expressão de emoções -, que encontram na disciplina dos sentimentos infantis instrumento importante de forja da cidadania política (REDDY, 1997). Menos restrito à dimensão imaterial das ideias, o capítulo de Susan A. Miller (capítulo 9) aborda a educação política de adolescentes norte-americanos na década de 1930 em encontros promovidos pela American Legion, associação de veteranos da Primeira Guerra. O culto ao americanismo, definido no artigo como uma imbricação de fé patriótica e compromisso emocional, buscava, por meio do engajamento afetivo de adolescentes, estimular o fortalecimento de identidades cívicas que assegurassem

\footnotetext{
${ }^{3}$ A referência aos livros Vigiar e punir e História da sexualidade repete-se em ainda outros capítulos do livro (FOUCAULT, 1977; 1985).
} 
a defesa da pátria contra as ameaças representadas pelo comunismo e a crise econômica no período entre guerras.

Retomando o tema do imaginário moderno da família discutido nos capítulos que tratam da Índia colonial, M. Colette Plum (capítulo 11) descreve políticas de acolhimento da infância orfanada pela guerra sino-japonesa (1937-1945), projetadas pelo Partido Nacionalista com o objetivo de inculcar nas crianças o revanchismo contra o Japão e a adesão a uma identidade nacional refratária ao comunismo e unificadora das disparidades regionais chinesas. A incorporação à "família nacional", assim, preencheria a lacuna da comunidade familiar de origem, prevenindo o desengajamento de crianças órfãs, vistas como ameaçadoras à ordem instituída, por meio do controle das experiências afetivas nas instituições de acolhimento.

Significativamente, o recurso à educação emocional da infância e juventude como instrumento de forja do pertencimento a comunidades políticas foi utilizado também no espectro oposto no mundo polarizado da Guerra Fria. Por meio de uma interessante abordagem da pedagogia musical aplicada à educação de crianças e jovens, que se vale da análise de livros didáticos e composições musicais, Juliane Brauer (capítulo 10) revela os usos do canto coletivo na Alemanha Oriental como estímulo aos sentimentos de alegria e contentamento que expressassem as virtudes e a superioridade do projeto socialista e, afinal, ensejassem o engajamento coletivo de crianças e adolescentes na comunidade organizada em torno dele.

$\mathrm{O}$ cultivo dos sentimentos de alegria e contentamento surge, igualmente, no capítulo de Kathleen Vongsathorn (capítulo 4) a respeito de um leprosário infantil comandado por missionárias inglesas em Uganda, entre as décadas de 1930 e 1960. Neste contexto, a evangelização e a busca pela alegria emanante de Cristo eram as chaves para a conversão de crianças "doentias" em pequenos "sadios e felizes", expressão de um processo imperialista e civilizatório que as afastaria de suas famílias para, finalmente, convertê-las em crianças conformes às definições de infância moderna universal. Também no capítulo de autoria de Hugh Morisson (capítulo 5), a respeito da Nova Zelândia colonial de fins do século XIX e inícios do $X X$, o estímulo ao cultivo da alegria encontrada na evangelização, nas práticas e na comunhão cristãs apresentam-se como instrumentos de engajamento de crianças em identidades comunitárias.

Finalmente, o instigante capítulo de autoria de Lydia Murdoch (capítulo 13), que encerra o volume, vale-se de uma leitura das campanhas anti-vacinação da Inglaterra vitoriana para demonstrar a sobreposição do imaginário da infância à cultura política. Mobilizando as representações da inocência infantil e dos rituais de luto pela morte de crianças, que ganham importância e significados públicos diante da consolidação de concepções modernas de infância no século XIX, militantes encontravam no movimento antivacina plataforma para a agência política dos segmentos marginalizados da sociedade - incluindo-se, aí, expressões populares do feminismo sufragista. Associando a idealização da vulnerabilidade infantil à linguagem dos direitos individuais, disputavam a participação na cidadania liberal que lhes era recusada.

Interessante e diversa compilação de abordagens metodológicas e contextos históricos, os capítulos do livro desenham, em conjunto, a eleição de temas e argumentos transversais. As concepções modernas da fragilidade infantil, bem como do caráter flexível da infância, que faziam das crianças sujeitos preferenciais 
do aprendizado de valores comunitários e, no limite, nacionais, sublinham todas as seções do volume. Compreensões ambíguas da infância, tão bem exploradas pelos intelectuais nacionais dedicados ao estudo da educação infantil no Brasil da virada do século XIX ao XX, são tema exclusivo do capítulo de M. Colette Plum a respeito das crianças órfãs chinesas. ${ }^{4}$ Tal acento sobre a maleabilidade e vulnerabilidade da infância sinalizam a importância, entre os séculos XIX e XX, da educação emocional de crianças com vistas à construção de novos desenhos de hierarquias sociais em âmbitos locais e globais. Instrumento de consolidação de projetos nacionais ou imperiais, o disciplinamento dos sentimentos infantis mapeado pelos autores nos diferentes contextos analisados situa as crianças no centro de projetos políticos que fazem delas veículos de discursos carregados de subjetividades a serem assimiladas pelos indivíduos e partilhadas em sociedade.

Esse potente argumento, que responde pelo maior interesse despertado pela perspectiva global adotada pelo livro, é, também, sua maior fragilidade. Irregulares em seus resultados, os capítulos, de modo geral, fazem da infância e das emoções a ela associadas uma plataforma para discussão de outros temas. Esta estratégia, que não é, por princípio, problemática, trai uma das promessas feitas logo na Introdução do livro, que é a de que "as emoções permitiriam e renovariam o acesso à agência e às vozes infantis". O que se verifica, ao longo dos capítulos, é a subalternização do tema da agência infantil a análises sobre conjunturas, disputas políticas, projetos imperiais e nacionais atinentes à dinâmicas globais que deixam muito pouco espaço à compreensão dos significados sociais das emoções ensinadas a crianças e por elas experimentadas. Há exceções, é verdade. Sobretudo os capítulos que se propõem a contemplar a performatividade das emoções inculcadas na infância por meio de políticas sociais e pedagógicas, como os de Kozlovsky, Brauer e Plumm, os quais abrem janelas à compreensão das relações entre o aprendizado e a prática das emoções em chaves menos prescritivas, afirmando a importância das próprias crianças como sujeitos das transformações sociais e políticas em análise. Em outras oportunidades, as crianças são personagens secundários nas interpretações propostas, como é o caso dos capítulos de Caruso, acerca da educação iluminista nos discursos de estadistas da nascente república colombiana, e de Banerjee, sobre a reelaboração do estatuto colonial de masculinidade e paternidade na região indiana de Bengala entre os séculos XIX e XX. No conjunto, o livro é menos uma obra sobre as relações entre crianças, jovens e emoções na história do que um estudo sobre as apropriações políticas de concepções de infância e juventude por meio de discursos de teor emocional. A atenção demasiadamente ligeira às implicações de classe, gênero e, principalmente, raça, na construção política e social das concepções de infância em discussão acentua a impressão de que a potente abordagem global anunciada dificulta a apreensão de formas concorrentes e conflitantes de conceber e experimentar a infância.

Outro aceno feito na Introdução, o de explorar representações simbólicas da infância e sua associação a valores e discursos de caráter emocional, esvazia-se, por vezes, diante de abordagens formalistas que pouco refletem a prática social. Neste sentido, o capítulo de Murdoch sobre o movimento antivacina destaca-se justamente

\footnotetext{
${ }^{4}$ Ver, entre outros, o trabalho de Irene Rizzini (2008).
} 
por oferecer um olhar inventivo sobre a cultura política vitoriana a partir de complexas relações e disputas sociais que mobilizam concepções emergentes de infância, aprofundando, assim, o que poderia ser uma conclusão mais genérica acerca da importância do signo infantil nas disputas políticas da época.

O saldo geral da avaliação do livro, não obstante, permanece positivo. A perspectiva global de fato tem a virtude de iluminar um processo ampliado de elaboração dos significados da infância em íntima ligação com dinâmicas políticas e, no limite, econômicas, de dimensões e impactos que transcendem realidades exclusivamente coloniais ou nacionais. Além disso, diversos capítulos apresentam um uso inovador de metodologias e fontes de modo a dar conta de documentar e interpretar a inserção de crianças, sujeitos politicamente marginalizados, nesse abrangente cenário. Por vezes, o engajamento das próprias crianças nas disputas encerradas nesses processos ampliados - frestas do "mundo que as crianças fizeram", para emprestar as bonitas palavras do clássico de Eugene Genovese - é também contemplada. É nesses momentos, e também naqueles em que as complexidades do signo infantil são investigadas em maior profundidade, que a perspectiva global tem seus lances mais felizes na obra como um todo.

\section{REFERÊNCIAS}

ARIÉS, Philippe. História social da criança e da família. Rio de Janeiro: LTC, 1918.

$\mathrm{COHN}$, Clarice. Concepções de infância e infâncias: um estado da arte da antropologia da criança no Brasil. Civitas: revista de Ciências Sociais, v. 13, n. 2, p. 221-244, 2013.

FLANDRIN, Jean-Louis. Enfance et societé: note critique. Annales, v. 19, n. 2, p. 322-329, 1964. Disponível em: https://www.persee.fr/doc/ahess_0395-2649_1964_ num_19_2_421149. Acesso em: 15 nov. 2018.

FOUCAULT, Michel. Vigiar e punir: nascimento da prisão. Petrópolis: Vozes, 1977.

FOUCAULT, Michel. História da sexualidade. Rio de Janeiro: Graal, 1985.

GREW, Raymond. On seeking global history's inner child. Journal of Social History, Oxford, v. 38, n. 4, p. 849-858, 2005.

HARDMANN, Charlotte. Can there be an anthropology of children? Childhood, v. 8, n. 4, p. 501-517, 2001.

HEYWOOD, Colin. Uma história da infância: da Idade Média à Época Contemporânea no Ocidente. Porto Alegre: Artmed, 2004.

JAMES, A.; PROUT, A (orgs). Constructing and reconstructing childhood: contemporary issues in the sociological study of childhood. Londres: The Palmer Press, 1990.

KHULMANN JR., Moysés; FERNANDES, Rogério. Sobre a história da infância. In: FARIA FILHO, Luciano Mendes (org.). A infância e sua educação: materiais, práticas e representações. Belo Horizonte: Autêntica, 2004.

REDDY, William M. Against Constructionism: the historical ethnography of emotions. Current Anthropology, v. 38, n. 2, p. 327-351, 1997. 
ROSENWEIN, Barbara. Worrying about emotions in history. American Historical Review, v. 107, n. 3, p. 821-845, 2002.

RIZZINI, Irene. O século perdido: raízes históricas das políticas públicas para a infância no Brasil. Rio de Janeiro: Editora Santa Úrsula; São Paulo: Cortez, 2008.

STEARNS, Peter N; STEARNS, Carol Z. Clarifying the history of emotions and emotional standards. American Historical Review, v. 90, n. 4, p. 813-836, 1985.

\section{NOTAS}

Marília Bueno de Araújo Ariza: Doutora. Pesquisadora autônoma, São Paulo, SP, Brasil. Rua Capote Valente, 149, 05409-000, São Paulo, SP, Brasil.

Como citar: ARIZA, Marília Bueno de Araújo. Acertos e desafios de uma perspectiva global da história da infância e das emoções. Esboços, Florianópolis, v. 26, n. 41, p. 197-205, jan./abr., 2019. [Seção] Resenha. Resenha da obra de: OLSEN, Stephanie (ed.). Children, youth and emotions in modern history: national, colonial and global perspectives. Basingstoke: Palgrave Macmillan, 2015. 264 p.

\section{FINANCIAMENTO}

Não se aplica.

\section{APROVAÇÃO DE COMITÊ DE ÉTICA EM PESQUISA}

Não se aplica.

\section{CONFLITO DE INTERESSES}

Não se aplica.

\section{LICENÇA DE USO}

Este artigo está licenciado sob a Licença Creative Commons CC-BY Internacional 4.0. Com essa licença você pode compartilhar, adaptar, criar para qualquer fim, desde que atribua a autoria da obra.

\section{PUBLISHER}

Universidade Federal de Santa Catarina. Programa de Pós-graduação em História. Portal de Periódicos UFSC. As ideias expressadas neste artigo são de responsabilidade de seus autores, não representando, necessariamente, a opinião dos editores ou da universidade.

\section{HISTÓRICO}

Recebido em: 15 de novembro de 2018

Aprovado em: 21 de dezembro de 2018 